\title{
Real Wages as Determinant of Labour Productivity in the Mexican Tourism Sector
}

\author{
Juan Gabriel Brida ${ }^{1 *}$, Wiston Adrián Risso ${ }^{2}$ and Edgar J. Sanchez Carrera ${ }^{3}$
}

Received: 10/09/2009 Accepted: 01/12/2009

\begin{abstract}
${ }^{1}$ Competence Centre in Tourism Management and Tourism Economics (TOMTE), School of Economics and Management - Free University of Bolzano, Universitätsplatz 1 - piazza Università, 1, I - 39100. Bolzano, Italy; phone: +390471013492, fax: +390471013 009, e-mail: JuanGabriel.Brida@unibz.it.

2 Department of Economics - University of Siena, Italy; phone: +39 0577 235058, fax: +39 0577 232661, e-mail: risso@unisi.it

${ }^{3}$ Department of Economics - University of Siena, Italy; phone: +39 0577 235058, fax: +39 0577 232661, e-mail: sanchezcarre@unisi.it

* Corresponding author
\end{abstract}

\begin{abstract}
In this paper we use time-series techniques to estimate the long-run relationship between real wages and labour productivity in the Mexican tourism. Using yearly data from 1970 to 2004, we find a cointegration relationship showing that the average labour productivity depends positively on real wages. We show that real wage is weakly exogenous and causes labour productivity. Moreover, the impulse-response function shows that a positive shock in real wages produces a small negative effect in productivity for two years followed by a large positive one.
\end{abstract}

(c) 2010 International University College. All rights reserved

Keywords: Labour Productivity, Real Wages, Cointegration test

Citation: Brida, J.G., W.A. Risso, E.J.S. Carrera (2010) Real Wages as Determinant of Labour Productivity in the Mexican Tourism Sector. European Journal of Tourism Research 3(1), pp. 67-76

\section{Introduction}

The best known and most meaningful expression of economic productivity is the productivity of labour, which can be expressed as the value added per employee. Moreover, output per worker is often used as the main measure of productivity because it is straightforward to quantify, since the data - total output and employment - are readily available and can be linked to the objective of raising total output growth.
Recruiting highly-skilled workers is quite a guarantee for any successful tourist firm. Labour productivity in tourism sector is a source of growth and this includes education, qualifications and training of people employed in this sector. Inadequate tourist education and lack of qualifications in an ethnic perspective, have dreadful consequences in tourist productivity (Trasury, 2003 and Eaglen et al., 2000). Moreover, investment in information 
technology and communication contributes enormously in productivity tourism and then, high-skilled workers in the tourist sector enable tourist efficiency (see Jacob et al., 2003). Productivity in tourism sector has been investigated recently by a number of researchers (Blake et al., 2006; Such and Zamora, 2006; Peypoch and Solonandrasana, 2006 and 2008; Brida et al., 2008).

In this vein, Blake et al. (2006) identified three classical measures of productivity in tourism: i) output per worker, ii) output per hour of labour and, iii) the total factor productivity. As Blake et al. pointed out, increases in wages and profits can be achieved by increases in competitiveness, driven by rising productivity. In tourism, productivity refers to the efficiency and optimal allocation of the used resources, by relating the quantity of labour and capital, to outputs. $^{1}$

There are large differences among the tourism destinations where the developing countries have the highest productivity of labour. Depending on the level of development, labour productivity in tourism will be either less than or greater than the productivity of the economy as a whole. In the most developed tourism countries the value added per employee in tourism is somewhat lower than the general level of productivity.

This paper aims to study the relationship between the real wages and the labour productivity in the tourism sector. The following papers, suggest the existence of a positive relationship between real wages and productivity:

- Marquetti (2004) is an empirical study of the relationship between real wage and productivity for the US economy, but they explain that technical change as being biased toward labour-saving.

- Gordon (1987) studies the dynamic behaviour of changes in productivity, wages and prices for the U.S., Japan, Europe, showing that the shift from high to low real wage growth is responsible for a substantial proportion of the decline in productivity growth in industrial sector for the three studied economies.

- Hibbs and Locking (2000) study the wage dispersion and the productivity in Sweden, showing that a reduction of the real wages differential contribute positively to an aggregate output and productivity growth.

In the present paper, at first, we set a theoretical model to explain the relation between real wages and labour productivity in the Mexican tourism sector. Typically the main parts of tourism expenditures are related with hotels and restaurants which are very labour intensive personal services. For this reason, we focus on a production function of tourism depending only on labour. As second step we find a long-run relationship between these two variables in the Mexican tourism sector during the period 1970-2004. The third step is to investigate causal linkage between real wages and labour productivity. This is the central aspect of the study and the main hypothesis is that an increase in real wages reduces the labour demand due to rigidities in the labour markets. ${ }^{2}$

In order to study the causal relationship we apply the Granger-causality test. In fact, this issue of increasing real wages by increment in productivity is the concept of efficiency wages which has been widely explored in labour economics. While initial increases in real wages may help in increasing productivity and therefore profits of the firm, after a point, the costs to the employer of further increases in real wages will exceed the benefits. But firms may offer above-market real wages in order to have a positive effect on worker turnover, effort, morale and productivity; this is known as efficiency wages (Katz, 1986; Murphy and Topel, 1990). Since the model in this paper does not differentiate in the quality of labour used, then different wages rates paid to qualitatively similar workers in the tourism sector is the hypothesized result of efficiency wage considerations. Thus the Grangercausality from real wages to labour productivity can be interpreted as the result of efficiency wages. 
To the best of our knowledge, this is the first paper that discusses the issue of long-run equilibrium relationship between labour productivity and real wages into a framework of tourism economics. The paper is organized as follows. Section 2 proposes a theoretical model explaining the positive relationship between real wages and labour productivity. In Section 3 we estimate empirically the long-run relationship between the two variables by using Johansen co-integration test, some other test are applied such us Granger causality in order to study the direction of causality in the variables. Section 4 draws some conclusions.

\section{Labour Productivity}

As was mentioned, the tourism sector is typically labour-intensive personal services. Blake et al (2006) discusses in detail the three drivers of productivity in the tourism sector which are physical capital, human capital and technology and innovation. For the sake of simplicity, let us assume that the production function of tourism depends only on human capital or labour: ${ }^{3}$

$Y=f(L)=A L^{\alpha}$

where $A$ is total-factor productivity and $\alpha$ is the output elasticity of labour $L$, assuming decreasing returns $\alpha$ should be less than 1 . Labour productivity is generally speaking held to be the same as the "average product of labour" (that is, the ratio output-labour). Hence, in order to obtain the productivity of labor:

$$
\frac{Y}{L}=A L^{-(1-\alpha)}
$$

Let us assume that there is disequilibrium in the labour market and the level of employment is determined by the demand of labour. Equation (3) shows that the demand of labour depends negatively on real wages $(W)$, where $k$ and $\beta$ are constants: ${ }^{4}$

$$
L=L^{d}(W)=k W^{-\beta}
$$

Taking logarithms in (2) and (3) and substituting the labour function in the productivity function we obtain the relationship between the productivity of labour $(y / l)$ and the real wages $(w)$, note that both variable are in logs.

$\frac{y}{l}=\alpha_{0}+\alpha_{1} w$

where $\quad \alpha_{0}=[\log A-(1-\alpha) \log k] \quad$ is a constant term that captures total factor productivity and, $\alpha_{1}=(1-\alpha) \beta$ is a positive term. Notice that mathematically $\alpha_{1}$ should be equal to 1 , we will test this hypothesis later. At least, we expect to obtain a positive coefficient. Notice also, that decreasing returns $(\alpha)$ are just necessary in order to obtain a traditional labour demand with negative slope.

Note that the productivity of labour depends positively on real wage, where $\alpha_{1}$ is the elasticity of the productivity of labour on real wages. The explanation is as follows. A decrease in labour demand produces an increment in labour productivity because both the existence of marginal decreasing returns of labour and the increment in real wages.

In this paper, we estimate, for the Mexican tourism sector, the wage-productivity elasticity. Our analysis is based on the assumption that the expected wage of an employee is a positive function of her/his productivity.

\section{Dataset and Methodology}

We consider annual data during the period 1970-2004 in order to study a cointegrated VAR setting approach. We consider yearly time series for the labour productivity, $(Y / L)$, measured as the ratio GDP /employees and real wages $(W / P)$ in the tourism sector. In our exercise hotels and restaurants are used proxy of the Mexican tourism sector. In particular, $\mathrm{Y}, \mathrm{W}$ and $\mathrm{L}$ are respectively GDP, number of workers and average real wages of the Mexican hotel and restaurant sector. The data was collected by the Center of Studies of the Chamber of Deputies, available at http://www.cefp.gob.mx/intr/e-stadisticas/. 
Because most macroeconomic variables are trended, time series can potentially create problems of finding spurious regressions when they are non-stationary, (see Phillips (1986) for an analysis of spurious regressions). Classical econometrics is not applied when the process is non-stationary and cointegration method should be applied. Therefore as a first step we have to study the integration order of the series in order to applied cointegration method. One method is the procedure proposed by Engle and Granger (1987). However, this method assumes the existence of only one cointegration relation. Most general procedure was proposed by Johansen (1988) and Johansen and Joselious (1990), this test has the advantage of testing all the possible cointegration relationship.

Banerjee et al. (1993) highlights the important connection between a cointegration relationship and the corresponding long-run equilibrium equation. Studying a cointegration relation is analyzing a statistical equilibrium between variables tending to grow over time. The discrepancy of this equilibrium can be modelled by a Vector Error Correction (VEC) model which shows how after a shock the variables come back to the equilibrium. Gobbin and Rayp (2008) pointed out that a cointegrated VAR-setting approach is the proper way to cope and avoid the problems of parameter heterogeneneity, omitted variable bias and endogeneity of the variables.

Hence, to study short- and long-run relationships between $(Y / L)$ and $(W / P)$, we follow the next procedure:

1) A first step in cointegration analysis is to study the stationarity of the series by using unit root tests, two popular techniques have been used: the Augmented Dickey-Fuller (ADF, 1981) and the Kwiatkowski-Phillips-SchmidtShin (KPSS, 1992) test. These tests have been performed in levels (i.e., log of $Y / L$ and log of $W / P$ ) as well as in the first difference (i.e., labour productivity and real wages).

2) An unrestricted Vector Autoregressive (VAR) is estimated, which is known to be sensitive to the number of time lags (Banerjee et.al., 1993). For determining the appropriate number of time lags of VAR the following criteria were employed: Akaike Information Criterion (AIC) and Schwartz Bayesian Criterion (SBC).

3) The existence of a long-run relationship between the variables is examined via a Vector Error Correction (VEC) model after applying the Johansen's cointegration technique (1988, 1990, and 1995). A test for weak exogeneity is conducted in order to do inference. ${ }^{5}$

4) Finally, Granger Causality test is done to detect the direction of the causality among the variables. The most important part of running Granger-causality tests is to justify why these causality tests are necessary in order to come to a conclusion regarding the causal relationship between two variables; in this case, the two variables are labour productivity and real wages.

Cointegration by itself does not indicate the direction of the causal relationship. Granger (1988) proposed a test to study causality. However, this is not causality in a philosophical sense. It should be understood as a kind of predetermination among variables. The dynamic Granger causality can be captured from the VAR model. To test the causality relationship among variables: labour productivity, and real wages; we specify the following Vector Auto Regressive (VAR) model:

$$
\left(Y / L(A)_{t}, W / P(A)_{t}\right),
$$

all of them in a given country $A$ at time $t$. If the two times series are integrated of the same order then the estimation of a cointegration regression has been considered. Thus, we search for a long-run relationship among the two variables and then, a Vector ErrorCorrection (VEC) model is applied to model the short-run dynamics. The model is represented in a first-differenced error correction form:

$$
\Delta X_{t}=\mu+\Pi X_{t-1}+\sum_{i=1}^{i=k-1} \Gamma_{i} \Delta X_{t-i}+\varepsilon_{i}
$$


where $\quad X=($ Labour Productivity $Y / L$, Real Wages W/P) is a vector containing the variables and $\mu$ is a vector of constant terms. The matrix $\Gamma$ conveys information about the long-run relationship between the $X$ variables. The rank of $\Pi$ is the number of linearly independent and stationary linear combinations of the variables. The final term in (5) $\varepsilon_{t}$, is in this case a $2 \times 1$ vector of error terms satisfying the usual assumptions in a Vector autoregression (VAR), that is: 1) $\varepsilon_{t}$ has mean zero, 2) the contemporaneous covariance matrix is positive definite, and 3) there is no correlation across time; in particular, no serial correlation in individual error terms.

\section{Unit root test and cointegration}

The spurious regressions problem is well known in econometrics. It generally happens that time series are non-stationary producing significant OLS parameter estimations and high $R^{2}$. However, the regression residuals are not stationary violating the classical assumption.
The spurious regression problem was remarked by Phillips (1986), in this case, Cointegration techniques have to be applied. The first step in cointegration analysis is to study the integration order of the series. Even if there are many unit root test, we will apply famous Augmented Dickey-Fuller test (ADF) and the KPSS test. As is well known, the null hypothesis in the case of ADF-test is that the process is integrated I(1) and it is accepted unless there is strong evidence against it. KPSS test has stationarity as null hypothesis complementing ADF test which has low power against stationary near unit root processes. Therefore a stationary process rejects the null hypothesis for ADF but it does not in the case of KPSS test.

Table 1 and 2 show unit root test for the logarithm of the variables in levels and in differences. According to tests, time series are integrated processes of first order, I(1), hence the classical econometrics is not applied and

Table 1: Unit Root Test result: Levers

\begin{tabular}{|l|l|l|l|l|}
\hline Variable & \multicolumn{2}{l|}{ Y/L } & \multicolumn{2}{l|}{ W/P } \\
\hline Unit Root Test & ADF & KPSS & ADF & KPSS \\
\hline Trend, Constant & -2.320 & 0.139 & -2.676 & 0.088 \\
\hline Constant & -1.080 & 0.322 & -0.912 & $0.530^{*}$ \\
\hline Without Trend, Constant & 0.217 & & -0.558 & \\
\hline
\end{tabular}

Table 2: Unit Root Test result: First Difference

\begin{tabular}{|l|l|l|l|l|}
\hline Variable & \multicolumn{2}{l|}{ Y/L } & \multicolumn{2}{l|}{ W/P } \\
\hline Unit Root Test & ADF & KPSS & ADF & KPSS \\
\hline Trend, Constant & 4.190 & 0.164 & 4.807 & 0.120 \\
\hline Constant & 4.153 & 0.230 & 4.830 & 0.127 \\
\hline Without Trend, Constant & 4.216 & & 4.855 & \\
\hline
\end{tabular}

* Null Hypothesis Rejection at 5\% 
we have to study the existence of a cointegration relationship. One method is the two-step procedure proposed by Engle and Granger (1987). However, this method assumes the existence of only one cointegration relation. Most general procedure was proposed by Johansen (1988) and Johansen and Juselius (1990), this test has the advantage of testing all the possible cointegrating relationship.

Banerjee et al. (1993) highlights the important connection between a cointegration relationship and the corresponding long-run equilibrium equation. Searching for a Cointegration relation is searching for a statistical equilibrium between variables tending to grow over time. The discrepancy of this equilibrium can be modelled by a Vector Error Correction (VEC) model which shows how after a shock the variables come back to the equilibrium.
At first, in order to apply the best Vector Autoregressive Model (VAR), the minimum AIC criterion is applied suggesting the use of 1 lag, this seems to be sense because the dataset dimension. In Table 3, the Cointegrating test suggests the existence of a long-run relationship between the real labour productivity $\mathrm{Y} / \mathrm{L}$ and real wages $\mathrm{W}$ in the tourism sector.

Note in Table 4 that in the long-run, the labour productivity is positively related with the real wages and the t-statistics is highly significative.

In order to do inference we should at least check weak exogeneity. In fact, the existence of weakly exogeneity permits to use the estimated equation without modelling the variable that we do not consider endogenous to the model. McCallum (1984) presents a clear example about the importance of studying exogeneity.

Table 3: Unrestricted Cointegration Rank Test

\begin{tabular}{|llllll|}
\hline $\begin{array}{l}\text { Trend assumption: } \\
\text { Series: }\end{array}$ & $\begin{array}{l}\text { No deterministic trend } \\
\text { Y/L, W/P }\end{array}$ & & & \\
\hline Trace & & & & & \\
\hline Hypothesized number of CE & Eigenvalue & Trace Stat. & Critical Value & Prob. \\
\hline None $^{*}$ & 0.349904 & 15.76386 & 15.49471 & 0.0455 \\
At most 1 & 0.060103 & 1.983513 & 3.841466 & 0.1590 \\
\end{tabular}

Table 4: Cointegrating Vector

\begin{tabular}{|lll|}
\hline Y/L & W/P & const. \\
\hline 1 & -0.816020 & -3.109890 \\
& {$[-5.11747]$} & \\
\hline
\end{tabular}

Table 5: Weakly exogeneity of Real Expenditure and test of $\alpha_{1}=1$

\section{Cointegrating Restrictions:}

$B(1,1)=1, B(1,2)=-1, A(2,1)=0$

Restrictions identify all cointegrating vectors

LR test for biding restrictions (rank $=1$ )

$X^{2}(1)$ :

Probability:

Cointegration Equation after exogeneity and assuming $\alpha_{1}=1$

\begin{tabular}{lll}
$\mathrm{Y} / \mathrm{L}$ & W/P & const. \\
\hline 1 & -1 & -1.337748
\end{tabular}


Table 5 shows cointegrating equation after testing weak exogeneity and coefficient $\alpha_{1}=1$. In the present case the test does not reject weak exogeneity, then we can consider real wages as weak exogenous variable, and we do not need to model these variables. We also accept the hypothesis that $\alpha_{1}=1$ satisfying perfectly the conditions of our model. Cointegration implies that causality exists between the series but it does not indicate the direction of the causal relationship.

Table 6 shows long-run Granger causality between the variables. Note that the null hypothesis that Real Wages does not cause Labour Productivity is rejected; however,

Equation (6) shows the long-run equilibrium or cointegrating equation after testing weakly exogeneity. Firstly, we have obtained an elasticity of Labour Productivity respect to real wages around 0.73 , meaning that an increment of $100 \%$ in real wages produces a growth of the long-run labour productivity of $73 \%$. However, as mentioned in section 2, the elasticity of Labour Productivity respect to real wages should be equal to 1 , satisfying perfectly the model. We test the hypothesis using the LR test obtaining a $X^{2}$ - statistic equal to 3.274 and a p-value of 0.194 . Therefore, we do not reject the hypothesis that an increment in real wages has a proportional increment in labour productivity. Once more, this does not contradict the assumption of decreasing returns $(\alpha<1)$, since the coefficient $\alpha_{1}$ in the econometric regression is independent of $\alpha$ and the decreasing returns assumption is just necessary to obtain a negative slope labour demand function. Therefore, the final equation is:

$$
(G D P / L)_{t}=1.34+(W / P)_{t}
$$

Note that the real wage is weakly exogenous and in the long run, causes the Labour Productivity, then it is strongly exogenous.

Moreover, we study how Labour Productivity responds over time to shocks in the real wages. Note in Figure 1 that after a positive shock in real wages, the labour productivity presents a small negative effect for two years and a later greater positive response.

\section{Concluding remarks}

Labour productivity is defined as the output per worker. In the long run, labour productivity is a main factor of improvements in the living standard of workers and its contribution to total production is crucial. In particular, the labour productivity has an important place in the tourism production since this is a labour intensive sector. In this paper we studied the relationship between the real wages and the labour productivity in the Mexican tourism sector. A simple theoretical model was proposed. It assumes that the quantity of labour is determined by the demand due to disequilibrium in the labour market. In addition, it supposes decreasing return to scale in the production function. In microeconomics decreasing returns in labour permits to maximize the profit function obtaining a labour demand with negative slope. Decreasing returns to scale in Mexican tourism might be associated with problems of management of large, multi-unit firms. We can think of a firm in which production takes place by a large number of units doing the same thing but the different units need to be coordinated by the

Table 6: Pairwise Granger Causality Tests

\begin{tabular}{|lll|}
\hline Null Hypothesis & F - Statistic & Prob. \\
\hline REAL WAGES does not Granger Cause LABOURPROD. & 5.38505 & $0.010^{*}$ \\
LABOURPROD does not Granger Cause REAL WAGES & 1.22975 & 0.308 \\
\hline
\end{tabular}


Response to Cholesky One S.D. Innovations

Response of Labour Productivity to Real Wages in Tourism Sector

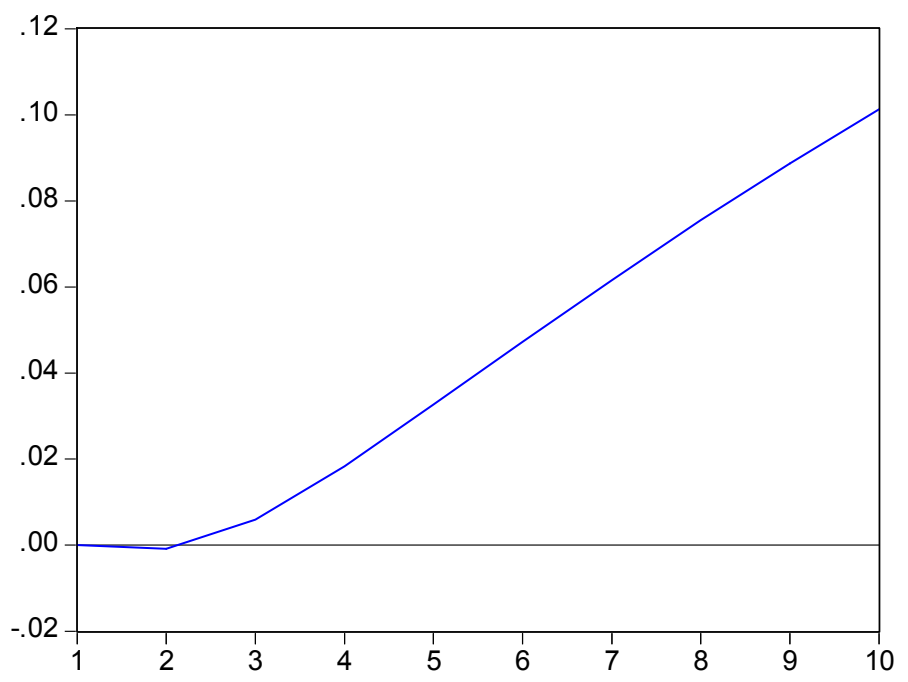

Figure 1: Impulse Function

central management. The management faces a trade-off. If it is not spent much on management, the coordination will be poor, leading to waste of resources, and higher cost. If so much is spent on management, that will raise costs in itself. The idea is that the bigger the output is, the more units there will be, and the worse this trade-off becomes, so the costs rise either way.

An example of empirical findings of decreasing returns in tourism is Yang and Lu (2006). They found that the International tourist hotels (ITH) in Taiwan are operating at decreasing returns to scale. They suggest that ITHs are facing a highly competitive environment in Taiwan.

Therefore, the model derives a positive relationship between the variables. An increment in real wages produces a decrease in the demand of labour which increases the labour productivity due to the decreasing returns to scale. The latter theoretical relationship was empirically estimated for the Mexican case by using econometric methodology. In particular, Johansen cointegration test suggests the existence of a unique positive long-run relationship between labour productivity and real wage. In addition, real wages are weakly exogenous and Granger-causes the labour productivity of tourism. The elasticity is 1 which means that an increase in the real wage produces a proportional increase in the labour productivity in the long-run. The impulse-response function shows that a positive shock in the real wage has a small negative effect in productivity for two periods and then a high positive effect.

\section{Acknowledgement}

Our research was supported by the Free University of Bolzano, project: "Tourism, growth, development and sustainability - The case of the South Tyrolean region". A preliminary version of this paper was presented at the 4th International Scientific Conference "Planning for the Future - Learning from the Past: Contemporary Developments in Tourism, Travel \& Hospitality", University of Aegean, Rhodes island, Greece 3-5 April 2009.

\section{Endnotes}

${ }^{1}$ To measure the real productivity and the real wages in tourism, we consider some proxys variables like hotels, 
restaurants and entertainment (see section below on dataset and methodology).

2 See Song and Witt (2000), Li et al. (2005), Song and Li (2008) and Song et al. (2008) for references regarding the applications of econometric techniques in tourism industry.

${ }^{3}$ According to the dominant viewpoint in economic theory, productivity refers to the efficiency and optimal allocation of resources by relating the quantity of labor and capital to output. Hotels and restaurants are evidence of the capital essentiality to the tourism industry implying that capital input can be included as a variable of the production function. Note that there are alternative viewpoints, including theories about the production frontier and inefficiencies.

${ }^{4}$ Remember that the demand of labour results from the maximization of the profit $p A L-w L$, where $p$ is price and $w$ is nominal wage, and the firm controls $L$. After maximization we obtain equation (3) where $\alpha=1 /(1-\alpha)$ and $\mathrm{k}=(1 / \mathrm{A})^{1 /(-1)}$, and $W=W / p$. Decreasing returns are necessary to obtain a negative second derivative and thus to obtain a maximum.

${ }^{5}$ Cointegration by itself is proving a useful conceptual and empirical tool, that is, the economic notion of a long-run relationship between economic variables. However, to derive implications of cointegration for policy analysis, it is fruitful to check the exogeneity of such variables. Critically, the exogeneity of a variable depends on the parameters of interest, and on the purpose of the model, whether for statistical inference at least weak exogeneity should be tested. For example, McCallum (1984) asserts that incorrect signs can be produced if exogeneity is not studied

\section{References}

Banerjee, A.; Dolado, J.; Galbraith, J.; Hendry, D. (1993) Co-integration, ErrorCorrection, and the Econometric Analysis of the Non-Stationary Data. Oxford University Press.

Blake, A., Sinclair, M.T. and Soria Campos (2006) Tourism Productivity: Evidence from the United Kingdom. Annals of Tourism Research, 33(4), pp. 10991120.

Brida, J., Risso, A., Sanchez Carrera, E. (2008) Tourism's Impact on the Long-Run Mexican Economic Growth. Economics Bulletin, 3(21), pp. 1-8.

Dickey, D. A. and W. A. Fuller. (1981) Likelihood Ratio Statistics for Autoregressive Time Series with a Unit Root. Econometrica, 49(4), pp. 10571072.

Eaglen, Lashley and Thomas (2000) Modeling the Benefits of Training to Business Performance in Leisure Retailing. Strategic Change, 9(5), pp. 431-448.
Engle, R. and Granger, C., (1987) Cointegration and Error Correction: Representation, Estimation and Testing. Econometrica, 55(2), pp. 251276.

Gobbin N. and G. Rayp (2008) Different ways of looking at old issues: a time-series approach to inequality and growth. Applied Economics, 40(7), pp. 885-895.

Gordon, R., (1987) Productivity, wages and prices inside and outside of manufacturing in the U.S., Japan and Europe. European Economic Review, 31(3), pp. 685-739.

Granger, C. (1988), Some recent developments in a concept of causality. Journal of Econometrics, 39(1-2), pp. 199-211.

Hibbs, D. A. and Locking, H., (2000) Wage dispersion and productivity efficiency: Evidence for Sweden. Journal of Labour Economics, 18(4), pp. 755-782.

Jacob M., Tintore J., Guilo E., Bravo A., and J. Ulet (2003) Innovation in the tourism sector: results from a pilot study in the Balearic Islands. Tourism Economics, 9(3), pp. 279-295.

Johansen, S. (1988) Statistical Analysis of cointegration vectors. Journal of Economic Dynamics and Control, 12(23), pp. 231-254.

Johansen, S. and Juselius, K. (1990) Maximum likelihood estimation and inference on cointegration with applications to the demand for money. Oxford Bulletin of Economics and Statistics, 52(2), pp. 169-210.

Johansen, S. (1995) Likelihood-based inference in cointegrated vector autorregressive models. Oxford University Press, Oxford.

Katz, L. (1986) Efficiency Wage Theories: A Partial Evaluation. NBER Macroeconomics Annual, ed. Stanley Fischer, MIT Press: Cambridge, Mass.

Kwiatkowski, D., P. Phillips, P. Schmidt and Y. Shin. (1992) Testing the Null Hypothesis of Stationarity against the Alternative of a Unit Root. Journal of Econometrics, 54, pp. 159-178. 
Li, G., Song, H. and Witt, S.F. (2005) Recent Developments in Econometric Modeling and Forecasting. Journal of Travel Research, 44(1), pp. 82-99.

Marquetti, A.,(2004) Do rising real wages increase the rate of Labour-saving technical change? Some econometrical evidence. Metroeconomica, 55(4), pp. 432-441.

McCallum, B., (1984) On Low-Frequency Estimates of Long-Run Relationships in Macroeconomics. Journal of Monetary Economics, 14(1), pp. 3-14.

Murphy, Kevin M. and Robert H. Topel (1990) Efficiency Wages Reconsidered: Theory and Evidence. In Yoram Weiss and Gideon Fishelson (eds.) Advances in Theory and Measurement of Unemployment. London: Macmillan.

Peypoch, N. and Solonandrasana (2008) Aggregate Efficiency and Productivity Analysis in the Tourism Industry. Tourism Economics, 14(1), pp. 45-46.

Peypoch and Solonandrasana (2006) A Note on Technical Efficiency in Tourism
Industry. Tourism Economics, 12(4), pp. 653-657.

Song, H. and Witt, S.F. (2000) Tourism demand modelling and forecasting. Oxford: Pergamon.

Song, $\mathrm{H}$. and $\mathrm{Li}, \mathrm{G}$. (2008) Tourism demand modelling and forecasting - A review of recent research. Tourism Management, 29(2), pp. 203-220.

Song, H., Witt, S.F. and Li, G. (2008) Advanced Econometrics of Tourism Demand. New York: Routledge.

Such Jesùs, M. and Zamora, M. (2006) Spanish Productivity: A regional approach. Annals of Tourism Research, 33(3), pp. 666-683.

Treasury H. M. (2003) The Tourist Sector in the UK: A productivity analysis. London.

Yang, C., Lu, W., (2006) Performance Benchmarking for Taiwan's International Tourist Hotels. Information Systems and Operational Research, 44(3), pp. 229-245 